\title{
Análises de poder em disputa: Foucault e a virada pós-estruturalista nos Subaltern Studies
}

\author{
Power analysis in dispute: \\ Foucault and the poststructuralist turn in the Subaltern Studies \\ Camila Massaro de Góes
}

Resumo Os Subaltern Studies indianos surgiram no início dos anos 1980 com o objetivo de reescrever criticamente a história das classes subalternas na Índia, tendo como principal influência teórico-política o pensador italiano Antonio Gramsci. A partir de 1988 identificamos uma "virada pós-estruturalista" no trabalho subalternista, com destaque para a obra de Michel Foucault. Neste artigo buscamos chamar a atenção para a influência do pensamento pós-estruturalista no projeto subalternista, bem como retomar o conflito desta corrente teórica com as ideias marxistas, principalmente no que tange às teorizações sobre os modos de poder e dominação.

Palavras-chave Estudos Subalternos; Foucault; Pós-Estruturalismo; Marxismo.

Abstract The Indian Subaltern Studies arose in the early 1980 s with the intent to critically re-write the history of the subaltern classes in India. Their main theoretical and political influence was the Italian thinker Antonio Gramsci. Since 1988 we identified a "post-structuralist turn" in the subalternist work, especially with the work of Michel Foucault. In this article we seek to highlight the influence of poststructuralist thought in the subalternist project and resume the conflict between this theoretical current and Marxist ideas, especially concerning the theories on modes of power and domination. Keywords Subaltern Studies; Foucault; Post-Structuralism; Marxism.

\section{INTRODUÇÃO}

Os Subaltern Studies possuem uma trajetória complexa que compreende mais de duas décadas de desenvolvimento intelectual, desde o projeto idealizado por Ranajit Guha ${ }^{1}$ em fins da década de 1970. Buscando intervir no debate acerca

a Mestre em Ciência Política pela Universidade de São Paulo (USP).

1 Ranajit Guha, nascido em 1922, é um historiador indiano que editou os primeiros seis volumes da série Subaltern Studies: Writings on South Asian History (I, II, III, IV, V, VI), de 1982 a 1989. Suas publicações incluem: A Rule of Property for Bengal: An Essay on the Idea of Permanent Settlement (1963), Elementary Aspects of Peasant Insurgency in Colonial India (1983) e Dominance without Hegemony: History and Power in Colonial India (1997a). 
da história colonial da Índia, o historiador indiano recorreu à noção gramsciana de subalterno como forma de afirmar um posicionamento teórico e político contra o que considerava interpretações elitistas do contexto indiano, fossem elas colonialistas ou nacionalistas. Dessa forma, Guha abriu uma polêmica com seus interlocutores marxistas na Índia, defendendo uma abordagem criativa que não se reduzisse a termos economicistas e deterministas, e que propusesse como centro da análise a questão política. Daí a grande relevância da escolha do tema da subalternidade, como forma de destacar como o domínio da política na Índia era estruturalmente dividido. O desafio era grande: buscar uma interpretação que desse conta das relações sociais indianas, entrecortadas por questões de casta, gênero e classe, em um esquema interpretativo complexo e geral de poder.

A partir, principalmente, da coletânea Selected Subaltern Studies, lançada em 1988, entendemos que se deu uma virada pós-estruturalista ${ }^{2}$ na obra subalternista, que acompanhou um movimento mais amplo do pensamento político e das esquerdas em nível mundial. Acompanhando o colapso do comunismo soviético e os desfechos da Guerra Fria, deu-se um declínio do marxismo em meio ao pensamento radical. Nesse contexto, os Subaltern Studies passaram a ser pressionados a responder a questões postas pelo contexto acadêmico e político de fins da década de 1980 e início de 1990, simultaneamente a sua entrada na academia norte-americana, a partir da obra de Gayatri Spivak, que desde o lançamento de Can the subaltern speak?, em 1985, já solicitava respostas subalternistas e pautava suas reflexões a partir de questões como o papel do intelectual e a possibilidade de representação e fala dos subalternos.

A partir de então, os trabalhos do coletivo indiano ganharam uma ampla difusão, passando a se identificar, em linhas gerais, com todo o campo de estudos conhecido como "pós-colonialismo". Grosso modo, o que caracteriza essa corrente de estudos é principalmente o seu ecletismo teórico. Junto com a incorporação das críticas pós-estruturalistas de Foucault e Derrida, permanece a defesa do tema da subalternidade, numa tentativa de conciliar esta nova fase com o projeto fundacional, fortemente influenciado pelas ideias de Antonio Gramsci.

2 Pós-estruturalismo é o nome dado a um movimento na filosofia que teve início na década de 1960 e que pode ser melhor definido por meio dos pensadores que o compõe, dos quais destacam-se Jacques Derrida, Gilles Deleuze e Michel Foucault. Como explica James Williams (2012, p. 14-15), o pós-estruturalismo projeta o limite sobre o interior do conhecimento e sobre a compreensão estabelecida da verdade e do bem de maneira radical - "o limite não é comparado com o centro, nem equiparado a ele, nem lhe é dado algum tipo de papel moderador, no sentido, por exemplo, da maioria opondo-se à escuta de minorias. Antes, a alegação é de que o limite é o cerne" (Williams, 2012, p. 15). 
Uma das primeiras tentativas de repensar a aproximação do viés pós-estruturalista empreendida pelos subalternistas foi levada a cabo pelo historiador Dipesh Chakrabarty, cujos ensaios mais importantes foram registrados em Provincializing Europe (2000a). No caso de Chakrabarty e dos demais intelectuais vinculados aos Subaltern Studies, essa virada se deu principalmente a partir da incorporação de Michel Foucault como marco teórico e da adoção de sua crítica do sujeito soberano como autor e sujeito da autoridade, da legitimidade e do poder. Esse engajamento com as ideias pós-estruturalistas se dá a partir da premissa de que:

\footnotetext{
Não há nada como a "astúcia da razão" que garanta que todos convergem a um mesmo ponto final na história, a despeito de nossas diferenças aparentes e históricas. Nossas diferenças históricas de fato fazem diferença. Isso ocorre porque nenhuma sociedade humana é uma tabula rasa. Os conceitos universais da modernidade encontram conceitos, categorias, instituições e práticas preexistentes através dos quais foram traduzidos e configurados diferentemente (ChakrabarTy, 2000a, p. xxiI, em livre tradução).
}

Chakrabarty conclui que há uma diferença figurativa, de como um conceito é visualizado na prática, e suas diferentes facetas discursivas, em sua pureza abstrata, como distinção parcial descoberta. Disso o historiador tira outra conclusão, a de que as "ideias universais" que pensadores europeus produziram no período da Renascença ao Iluminismo, que desde então influenciaram projetos de modernidade e modernização em todo o mundo, jamais poderiam ser completamente universais, assim como os conceitos jamais poderiam ser completamente puros. Isso porque as próprias linguagens e as circunstâncias da formulação foram importadas de um contexto de histórias preexistentes que eram singulares e únicas. Chakrabarty indagava se "o pensamento pode transcender seu lugar de origem" ou ainda se "os lugares deixam suas marcas no pensamento de tal modo a colocar em questão a ideia de categorias puramente abstratas" (CHAKRABARTY, 2000a, p. XIII). Provincializar a Europa era, precisamente, descobrir em que sentido as ideias europeias vistas como universais eram, ao mesmo tempo, ideias elaboradas a partir de tradições históricas e intelectuais particulares que não poderiam reivindicar validade universal. Tratava-se, mais uma vez, de pensar como as ideias se relacionam com o lugar.

No pós-estruturalismo, valores e condições não são tidos nunca como identidades ou como regra lógica. Ao invés disso, os valores são puros movimentos e as condições formais são as condições necessárias para esses movimentos: 
necessárias para a resistência deles à identificação. Como argumenta Williams, essa perspectiva “começa 'onde você sente diferentemente' e não 'onde você sabe mesmo o que' ou 'segue as mesmas regras ou leis que'. Você então tenta encontrar as condições necessárias para a resistência deste sentimento a um retorno à identidade e à mesmice" (Williams, 2012, p. 89).

Tendo em vista sua presença marcante nos Subaltern Studies, vale a pena voltarmos a atenção para como Foucault desenvolveu, através de uma série de estudos históricos, o seu pós-estruturalismo. Sua obra é notável pela tentativa de mudar o modo como a história é escrita. Para Williams, ele é mais um filósofo-historiador do que simplesmente um ou outro, oferecendo novos modos de pensar a relação com o passado e fornecendo métodos complexos e poderosos para escrever a história. Sua obra é vista como uma ruptura revolucionária com o que veio antes, não só em termos da história, mas também de filosofias do tempo e do condicionamento do social. Em suma, é Foucault quem provê uma nova e pós-estruturalista forma de crítica histórica - daí seu papel central na segunda fase dos Subaltern Studies.

O "filósofo-historiador" é entendido como um anti-humanista, uma vez que se recusa a colocar o homem no centro da análise. Com isso, não há um "fora do sistema”, uma busca por um homem transcendental. A noção foucaultiana de sujeito é composta tanto pela agência, quanto pela sujeição, e a ação é possibilitada pelo processo de tornar-se sujeito enquanto se disciplina. Contra o humanismo fundacional, Foucault defende uma história em que o humano e a liberdade humana são partes de genealogias emergentes e não independentes delas. Nesse sentido, esperança e ação estão baseadas em estruturas complexas, e não fundadas externamente na transcendência do sujeito livre. Como muitos pós-estruturalistas, sua obra se coloca entre o determinismo e a liberdade.

Para o pensador francês, não existe de um lado os que têm poder e, de outro, aqueles que estão dele aleijados - rigorosamente falando, o poder não existe, existem, isso sim, práticas ou relações de poder. Dessa forma, o poder é algo que se exerce, que se efetua, que funciona como uma máquina social que não está situada em um lugar privilegiado ou exclusivo, mas que se dissemina por toda a estrutura social (MACHADO, 2010). O poder está nas estruturas, na capacidade de determinar identidades e atos, valores e normas. O poder é a rede de determinações históricas nas quais a luta se dá, das quais não podemos escapar, ao menos não completamente (Williams, 2012, p. 159). Se o poder é produtivo - onde está a agência? Em Foucault, a questão da sujeição marca a agência, não há nenhum 
agente que diga não ao poder, na medida em que se está intimamente envolvido com ele. Não há agente puro.

Ao enfatizar o condicionamento histórico, a contingência e a abertura, Foucault elabora críticas a um certo marxismo, insurgindo-se contra a ideia de que o Estado seria o órgão central e único do poder, e também ao liberalismo, por não acreditar em livres sujeitos humanos. Há aqui também uma problematização dos temas da ideologia e da repressão, caros a esse debate, a partir do que Foucault chama de genealogia, ou seja:

[...] uma forma de história que dê conta da constituição dos saberes, dos discursos, dos domínios de objeto, etc., sem ter que se referir a um sujeito, seja ele transcendente com relação ao campo de acontecimentos, seja perseguindo sua identidade vazia ao longo da história (Foucault, 2010, p. 7).

Foucault se afasta de uma análise centrada nos termos de ideologia e repressão e passa a destacar o corpo como a expressão e o sustentáculo das forças do poder e do saber. Em entrevista à Quel Corps?, em 1975, afirmava ser preciso afastar uma tese muito difundida, segundo a qual o poder nas sociedades burguesas e capitalistas teria negado a realidade do corpo em proveito da alma, da consciência, da idealidade. Na verdade, para Foucault, "nada é mais material, nada é mais físico, mais corporal que o exercício do poder" (Foucault, 2010, p. 147). Dessa forma, se afasta das análises marxistas e questiona se:

Antes de colocar a questão da ideologia, não seria mais materialista estudar a questão do corpo, dos efeitos do poder sobre ele. Pois o que me incomoda nestas análises que privilegiam a ideologia é que sempre se supõe um sujeito humano, cujo modelo foi fornecido pela filosofia clássica, que seria dotado de uma consciência de que o poder viria se apoderar (Foucault, 2010, p. 148).

Os intelectuais indianos recorreram a uma eclética fonte teórica que compreendeu de modo geral Marx, Gramsci e Foucault como principais referências ${ }^{3}$. Para Florencia Mallon (2009, p. 194), esta tentativa de "montar dois cavalos de uma vez" - nominalmente, Foucault para ressaltar a técnica e a genealogia e Gramsci para destacar a consciência e agência subalternas - revela uma tensão inerente. David Hardiman considera que "um caminho leva em direção a um maior foco

3 No caso da obra de Spivak, destaca-se também a influência de Jacques Derrida. 
nas análises textuais e na relatividade de todo saber, enquanto o outro leva em direção ao estudo da consciência e ação subalternas, a fim de encaminhar a luta por uma sociedade socialista” (HARDIMAN, 1986, p. 290). Ileana Rodriguez interpreta da seguinte forma:

No que diz respeito à relação entre metodologia e política - os dois pares de cavalos aos quais Mallon se refere, com Derrida e Foucault do lado metodológico e Gramsci e Guha do lado político - a questão é menos a de privilegiar o político sobre o cultural, mas precisamente o oposto: de demonstrar a impossibilidade de separar uma forma de representação da outra (Rodriguez, 2001, p. 6, em livre tradução).

Esse ecletismo - conflitando fontes teórico-políticas metropolitanas - é uma característica, na opinião de Spivak, do intelectual pós-colonial em cuja atividade devemos ver "a repetição e ao mesmo tempo a ruptura do predicamento colonial" (SPIVAK, 1988, p. 10). Este movimento ao ecletismo se dá no momento do reconhecimento internacional dos Subaltern Studies - entendidos como um projeto de resistência a discursos nacionalistas e hegemônicos, a partir de histórias do "subalterno" - o que, não surpreendentemente, coincidiu com a emergência do pós-estruturalismo e da crítica ao humanismo nos Estados Unidos. Houve, evidentemente, uma intersecção entre um movimento mais geral do pensamento político - principalmente das correntes intelectuais que conformaram a nova esquerda - e as investigações subalternistas.

Para Gyan Prakash (2000), o projeto dos Subaltern Studies se diferencia nesse contexto porque, ao mesmo tempo em que resgata o subalterno da vontade da elite colonial ou nacionalista, reivindica também a sua consciência. Esta tensão, entretanto, vai se dissolvendo ao longo do tempo e o projeto subalternista se torna cada vez mais uma resistência aos discursos hegemônicos nacionalistas e colonialistas, através de histórias do subalterno cuja identidade reside na diferença. A partir de então, a reflexão em torno do poder apresenta diferentes tons, colocando velhas questões em novas roupagens na agenda metodológica e política da época. A separação entre o saber e o poder, assim como a ideia do poder visto como unidade se torna mais difícil. A produção do senso comum, nesse sentido, não residiria em uma instituição, ao passo que o poder estaria presente em todos os aspectos da vida cotidiana. É ao redor dessas questões que podemos observar a presença do pós-estruturalismo de Foucault enquanto aporte teórico e metodológico para os intelectuais indianos. 


\section{GENEALOGIA E COLONIALISMO}

Por que Foucault se tornou importante para os estudos do colonialismo? Embora o filósofo francês não tenha se engajado diretamente com a mecânica do colonialismo, o seu pensamento é altamente influente nesse campo de conhecimento, na medida em que ajuda a pensar os mecanismos pelos quais o poder é construído e disseminado. Foucault escreveu sobre as formas nas quais o conhecimento é moldado pela produção do discurso, o qual sustenta, por sua vez, as estruturas de poder de uma dada sociedade. Em Arqueologia do Saber (2005), o filósofo-historiador formulou uma nova perspectiva para a compreensão da história, que se baseia não na continuidade, na tradição, na influência direta, no desenvolvimento ou no espírito subjacente, mas na identificação de rupturas e descontinuidades dentro dos e entre os discursos na história.

Foucault estava preocupado com padrões de identidade em torno de diferenças ou pontos de inflexão e mudança. Ele buscava não o que continua ao longo da história, mas o que se desenvolve e se torna outro. Essa transformação é mapeada e explicada observando-se as similaridades em torno de pontos de mudança, reunindo o que estava antes separado (WiLLIAMs, 2012). Uma vez que não faz uma distinção entre discurso e aplicação, Foucault resolutamente se afasta de uma noção de unidade - seu pensamento é sempre fragmentado, variável -, havendo uma permanente dinâmica em seus escritos sobre poder. Nesse sentido, torna-se difícil pensar em uma organização de resistência, afinal não há como pensar em partido político, tampouco na ideia de um tipo de resistência que só poderia tomar uma única forma. Assim, Foucault se torna útil para o propósito de codificação de projetos dentro do colonialismo, de modo a entender de perto como as identidades foram fixadas.

Para Partha Chatterjee (1988, p. 389), Foucault chamou a atenção para "a forma capilar de existência" do poder, "o ponto onde o poder atingiu o próprio grão dos indivíduos, tocou seus corpos e se inseriu em suas ações e atitudes, em seus discursos, processos de aprendizagem e na vida cotidiana". O século XVIII teria inventado, assim, seguindo o argumento foucaultiano, um "regime sináptico de poder", um regime de exercício do poder por dentro do corpo social, e não por cima dele. Essa mudança mais ou menos coerente nos modos de exercício de poder em pequena escala foi possível apenas por meio de uma mudança estrutural. Foi a instituição dessa nova forma de poder, local, capilar, que impeliu a sociedade a eliminar certos elementos tais como a corte e o rei. De acordo com Chatterjee, 
Foucault buscou demonstrar as complexidades desse novo regime de poder em seus estudos da história da doença mental, da prática clínica, da prisão, da sexualidade e do nascimento das ciências humanas. Quando se olha para os regimes de poder nos países chamados atrasados hoje, não somente a dominância de modos caracteristicamente "modernos" de poder parecem limitados e qualificados pela persistência de antigos modos, mas pelo fato de sua combinação em uma formação de Estado particular, que parece abrir ao mesmo tempo um novo ramo inteiro de possibilidades para as classes dominantes exercerem a sua dominação (ChATtERJEE, 1988, p. 389-390, em livre tradução).

Baseado em um estudo dos conflitos entre hindus e muçulmanos em Bengali, em More on Modes of Power and the Peasantry (1988), Chatterjee propõe novas formas de entender o processo histórico de transição em meio a esse fundo intelectual - buscando ligar a teoria social marxista com as noções de poder foucaultianas para defender a noção de "comunidade" como princípio primário de organização da mobilização política.

De 1925 até a divisão da Índia em 1947, o principal fator da política em Bengali foi o antagonismo comunalista marcado por uma série de conflitos de inédita difusão e intensidade. Chatterjee divide as explicações desse fenômeno em dois tipos. A primeira, colonialista, sugere que identidades e clivagens comunalistas são inerentes ao caráter essencial da sociedade indiana. A segunda, nacionalista, afirma que a divisão comunalista na Índia é produto das práticas coloniais. Há também uma variação de esquerda dessa última explicação, que argumenta que as divisões reais da sociedade indiana são as de classe e não as de comunidade - consequentemente, tanto o governo colonial quanto a ideologia e o líder comunalistas acabam por mascarar questões reais de classe para enfatizar as divisões de comunidade (ChATterJee, 1988). Chatterjee acredita que todas essas explicações comprometem a visão do fenômeno, que pertence propriamente a duas áreas completamente separadas de crenças e ações políticas:

Em todas as sociedades pré-capitalistas em processo de transição para formas de organização do Estado moderno, "política” só pode ser entendida em termos de interação destes dois domínios contrários. No primeiro, no qual crenças e ações são guiadas pela consciência popular, categorias tais quais “comunalismo" são inteiramente inapropriadas. O que pode ser propriamente chamado "comunidade" é de fato central para essa consciência, mas esta consiste em aspectos contraditórios e ambíguos. O outro domínio, formado pela política representa- 
tiva do Estado moderno, é onde novos modos de formação de classe emergem e se consolidam. É a intersecção desses dois domínios que se torna o principal ponto de investigação do processo transicional (ChatterJeE, 1988, p. 352, em livre tradução).

A partir desse cenário, Chatterjee (1988) busca refletir sobre conceptualizações básicas do problema geral da política e do Estado em sociedades agrárias amplas. Ao se afastar de análises deterministas com foco em termos técnicos e econômicos, o autor investiga os modos de poder, como por exemplo a forma pela qual direitos individuais ou seccionais, bem como deveres e encargos, são alocados na autoridade de todo grupo social, a comunidade.

O teórico indiano começa promovendo uma tipologia de três modos de poder - comunal, feudal e burguês - para explicar a evolução diferencial das relações sociais no campo indiano. $\mathrm{O}$ autor sugere que todos os três modos de poder poderiam ter coexistido, dentro de uma forma determinada de Estado na Índia colonial, mais precisamente, como um resultado direto das políticas coloniais britânicas, que impactaram diferentes partes da economia agrária. Chatterjee está interessado em examinar as relações de classe e conflitos dentro de cada modo de poder, de modo a demonstrar que mesmo dentro da Índia haveria indeterminação na transição para o capitalismo. Assim, para o autor, era necessário se afastar de uma perspectiva estritamente marxista de análise de classes, posto que a comunidade constitui um princípio organizativo da ação coletiva em cada modo de poder.

Assim, Chatterjee (1988) assinalou em que medida a indeterminação presente no processo de transição do desenvolvimento capitalista revela como não é apenas plausível, mas também provável que as características de um ou mais modos de poder tenham coexistido com a capitalista. O teórico indiano argumentou que essas circunstâncias não apenas propiciaram às classes dominantes a oportunidade de exercer sua dominação dentro do modo capitalista, na forma descrita por Foucault, mas também que essas classes contaram com a persistência de antigos modos de poder. A obra de Chatterjee sugere que um entendimento dos modos de poder na Índia ajuda a explicar como as elites dominaram, mas também lança luz sobre as diversas formas por meio das quais as classes subalternas contribuíram para a desmontagem dos modos de poder e sobre a complexidade da questão da transição dentro da Índia colonial. Como Chatuverdi afirma, nesse sentido "Chatterjee foi provavelmente o primeiro subalternista a se engajar com os escritos de Michel Foucault como forma de entender o modo de poder capitalista dentro do contexto indiano" (CHATUVERd, 2007, p. 13). 
Chakrabarty (2000a) também se aproveitou dos escritos pós-estruturalistas de Foucault, sobretudo como um importante estímulo para críticas ao historicismo. Para o subalternista, o "historicismo" foi o responsável pela imagem da modernidade, ou do capitalismo, não apenas como global, mas como algo que se tornou global ao longo do tempo, originário de um lugar - Europa - e que depois se propagou para fora dele. Essa estrutura do tempo histórico de "primeiro na Europa e depois em outro lugar" é, em sua visão, historicista:

Foi o historicismo que permitiu a Marx dizer que um "país mais avançado industrialmente apenas mostra, aos menos desenvolvidos, a imagem de seu futuro" [...] O historicismo, assim, postulou o tempo histórico como medida de distância cultural (ao menos em desenvolvimento institucional) assumido como existente entre o Ocidente e o Oriente. Nas colônias, legitimou a ideia de civilização (CHAKRABARTy, 2000a, p. 7, em livre tradução).

Dessa forma, o colonialismo garantiu, segundo Chakrabarty (2000a, p. 148), uma "Europa da mente" - "a Europa do liberalismo e do marxismo". O dever do historiador da modernidade colonial, nesse sentido, seria o de dar nova energia à palavra "nascimento" - da modernidade -, com todo o potencial que a restauração do pensamento de Nietzsche por Foucault liberou. Entender esse nascimento como genealogia e não como um ponto de clara ruptura de origem é, para Chakrabarty, abrir a questão da relação entre diversidade de práticas ou mundos da vida e a universalização das filosofias políticas, que permaneceram como herança do Iluminismo em nível global.

Em Provincializing Europe (2000a), um dos seus principais objetivos é entender como o pensamento crítico luta contra o preconceito (ao mesmo tempo em que carrega alguns de seus resquícios), bem como estabelecer em que medida ele está, acima de tudo, relacionado com o seu lugar. Dessa forma, em disputa com a teoria marxista, Chakrabarty busca criticar a ideia que se tem do local - direcionado principalmente aos que consideram o "local" como fenômeno superficial da vida social, sendo, em última análise, um efeito do capital. Para o autor, esse tipo de pensamento esvazia todo o sentido vivido de lugar, subsumindo-o a um nível assumido como mais profundo e determinador - o nível no qual o modo capitalista de produção cria um espaço abstrato. Ao contrário, para o historiador (2000a, p. 6) a "diferença não é sempre uma artimanha do capital”, e nem todo o aspecto do "local" pode ser mercantilizado. Nesse sentido, seu principal objetivo é desafiar dois conceitos centrais à ideia de modernidade: 
Um é o historicismo - a ideia de que para entender qualquer coisa, esta tem que ser vista como unidade e em seu desenvolvimento histórico - o outro é a própria ideia do político. O que historicamente permite um projeto tal qual o de "provincializar a Europa" é a experiência da modernidade política em um país como a Índia. O pensamento europeu tem um relacionamento contraditório com tal instância da modernidade política. É tanto indispensável como inadequado, pois nos leva a pensar por meio de várias práticas de vida que constituem o político e o histórico na Índia. Explorar - em ambos registros, teóricos e factuais - essa indispensabilidade simultânea e a inadequação ao pensamento das ciências sociais é o objetivo que este livro tem para si mesmo (CHAKRABARTY, 200oa, p. 6, em livre tradução).

Chakrabarty concorda com a derrota da obtenção de hegemonia e com os impasses da dinâmica universalista, mas enfatiza a derrota da busca por supremacia do capital na tentativa de transformar relações de poder. Nesse sentido, a persistência de antigas formas de poder não seria um index de um capitalismo incompleto, ou mesmo atrasado, mas sim consequências da variante não-universalista do capitalismo, que tem dinâmicas sociais diferentes do capitalismo original, universalista. Dessa forma, o capitalismo pode se propagar ao redor do mundo, mas as relações de poder que estabelece não serão idênticas. Muito embora essas relações sejam modernas, e contemporâneas ao desenvolvimento capitalista, Chakrabarty não as entende como formas burguesas de poder. Segundo essa perspectiva, o colonialismo na Índia propiciou novas relações de poder, que não podem ser subsumidas em uma história universal do capital, nem entendidas como uma instância das mesmas relações de poder capitalistas que emergiram durante a modernização europeia. Ou seja, se trata de um capitalismo, "mas sem hierarquias capitalistas" (CHAKRABARTY, 2000a, p. 21).

Deixando explícita uma leitura do subalterno que rechaça qualquer tentativa de compreensão de totalidade, Chakrabarty (2000b) busca uma reconciliação com as origens marxistas dos Subaltern Studies, propondo uma leitura de Gramsci que suprime seu engajamento político e enfatiza os aspectos que o marxista buscava superar no que dizia respeito ao caráter fragmentário das classes subalternas:

Como seria a história indiana se fosse imaginada como fragmentária? Não "fragmentária” no sentido de fragmentos que se referem a um implícito todo, mas fragmentos que desafiam não somente a ideia de totalidade, mas a própria ideia 
de "fragmento" (pois se não houvesse quaisquer totalidades, os "fragmentos" seriam "fragmentos" de que?) (CHAKRABARTY, 200ob, p. 274, em livre tradução).

Ir ao subalterno como forma de aprender a ser "radicalmente fragmentário e episódico" seria, na visão de Chakrabarty, se afastar da "monomania" da imaginação que opera dentro de uma visão em que o sujeito do conhecimento, do julgamento e do desejo sempre já tem conhecimento do que é bom para todos, antes de qualquer investigação. Ao contrário, a investigação deveria possuir:

Uma abertura tão radical que só pode ser expressa em termos Heideggerianos: a capacidade de ouvir o que ainda não se pode entender. Em outras palavras, permitir à posição subalterna desafiar nossas próprias concepções do que é universal, estar aberto a possibilidades de um pensamento de mundo particular, mesmo que possa estar preocupado com a tarefa de atingir a totalidade, tornando-o finito pela presença do Outro: tais são os horizontes utópicos aos quais esse outro momento dos Subaltern Studies nos chamam. As formas de conhecimento produzidas nesse fim não estarão amarradas ao Estado ou à governabilidade pois não refletirão vontade de governar. O subalterno aqui é a figura ideal de quem sobrevive ativamente, mesmo com alegria, no pressuposto de que os instrumentos eficazes de dominação sempre pertencerão a outra pessoa, sem nunca ansiar por eles (CHAKRABARTY, 200ob, p. 276, em livre tradução).

\section{COLONIZAÇÃO DO CORPO}

Outra investigação que ilustra bem a perspectiva foucaultiana se encontra no artigo de David Arnold, Touching the Body: Perspectives on the Indian Plague, 1896-19oo (1988). Aqui, o autor pretende entender a praga - que começou em 1896 e resultou em mais de 12 milhões de mortes - nos termos da relação em desenvolvimento entre elites nativas, classes subalternas e Estado colonial. De acordo com o autor, "a praga dramatizou a importância do corpo - o corpo, quer dizer, dos colonizados - como o lugar do conflito entre poder colonial e política nativa” (ARNOLD, 1988, p. 392).

Durante a fase inicial, o corpo tinha um significado medicinal, administrativo e social específico: grande parte do impulso intervencionista do Estado foi dirigido para a sua apreensão e controle, assim como grande parte das medidas de resistência à praga giravam em torno da ocultação ou evasão corporais. O corpo, entretanto, foi profundamente simbólico de um campo muito mais amplo e estável 
de contenção entre as percepções, práticas e preocupações nativas e coloniais, sendo que "o exercício do poder britânico tocou em muitas formas sobre a questão do corpo indiano" (ARNold, 1988, p. 392).

A analogia foucaultiana entre prisão e hospital, entre penalogia e medicina, foi mais evidente no recurso à hospitalização e segregação. Na percepção colonial, o ambiente físico e social da Índia foi visto como prejudicial ao corpo e bem-estar moral, constituindo tanto a causa quanto o contexto do crime e da doença. Arnold (1988) lembra que essa atitude deu origem não só à prisão, mas também aos reformatórios e aos assentamentos para "tribos criminosas".

Apesar da oposição à segregação e hospitalização ser geralmente expressa em um idioma da poluição masculina e da privação, foi a apreensão das mulheres e sua remoção para acampamentos e hospitais que provocou algumas das mais ferozes resistências. A oposição à intervenção médica ocidental era forte também entre aqueles indianos que viam a praga como uma forma de punição divina, como uma provação contra a qual o uso da medicina ocidental não passava de algo ímpio ou ineficaz.

Tampouco apenas o corpo vivo foi submetido a insultos e indignidades. $\mathrm{O}$ exame e a eliminação de cadáveres ocupou, desde cedo, um lugar proeminente na política de contenção de pragas. Arnold (1988) enfatiza que o assalto colonial ao corpo não foi a única causa da oposição às medidas anti-praga adotadas pelo governo; havia também uma preocupação com a perda de propriedades e bens, destruídos ou roubados durante as operações de praga. Mas o autor argumenta que "acima de tudo, era o real, ameaçado ou imaginado ataque ao corpo que despertou a maior raiva e medo nos anos iniciais da praga e foi a causa mais comum de evasão e contestação" (ARNOLD, 1988, p. 404).

Por fim, o autor afirma que os primeiros anos da epidemia de praga indiana forneceram uma ilustração importante da ação recíproca complexa de coerção e cooperação, resistência e hegemonia, classe e raça na situação colonial. Depois de analisar de perto as medidas de controle aplicadas pelo governo britânico, e valendo-se da noção de hegemonia de Gramsci, Arnold chega à seguinte conclusão:

A força da reação indiana resultou em uma reafirmação política sobre as considerações sanitárias e em uma alteração em relação a uma política de acomodação dirigida primariamente a ganhar suporte e cooperação da classe média. Coerção foi temperada com consenso. A resistência subalterna desempenhou um papel importante em arrancar essas concessões do Estado colonial, mas a hegemonia da classe média foi a principal beneficiária. Enquanto o conflito inicial sobre a 
administração da praga abriu uma divisão política e racial significativa entre dominantes e dominados, revelou também a importância de uma cada vez mais assertiva, ainda que não consolidada, ascensão da classe média sobre as massas indianas (ARNOLD, 1988, p. 426, em livre tradução).

Ainda seguindo uma interpretação da obra de Foucault, com uma visão da Índia colonial centrada em temas tais como a medicina, a prisão e a colonização do corpo, Arnold busca em outro trabalho, The Colonial Prison: Power, Knowledge, and Penology in Nineteenth-Century India (1997), contrastar a visão paradigmática francesa da disciplina prisional e da fiscalização institucional com uma perspectiva distinta, elaborada na Índia colonial. Baseado em Foucault, Arnold afirma que a prisão foi mais uma instituição penal e a penalogia mais um discurso sobre prisioneiros e punição. Na Índia, ao longo do século XIX, houve muitas ocasiões em que prisioneiros dominaram os guardas, tomaram a prisão e temporariamente ditaram os termos para as autoridades. Esses episódios ilustram as dificuldades que as autoridades encontraram para exercer controle disciplinar sobre os prisioneiros, especialmente nos primeiros sessenta anos desse século. A prisão, nesse sentido, se tornou um símbolo da rebelião contra a Inglaterra. Nesse contexto, o principal objetivo do autor é identificar o que os sistemas prisionais na Índia revelam de especificamente colonial. Para fazer isso, primeiro coloca-se contra Foucault e sua noção de que é possível achar evidências abundantes de resistência e evasão no sistema prisional e na rede de poder e, então, volta-se para as autoridades prisionais que exerceram escasso controle.

Para Arnold (1997), essa autoridade e controle limitados foi parcialmente resultado de uma escolha pragmática feita pelo regime colonial, um reconhecimento de sua prática e restrições políticas e, parcialmente, a expressão franca de seu interesse limitado nos propósitos estabelecidos da disciplina e reforma penal. Por outro lado, concordando com Foucault, o autor argumenta que:

A prisão foi, no entanto, um local crítico para a aquisição de conhecimento colonial e para o exercício - ou negociação - do poder colonial. Se uma das principais ambições de Foucault era mostrar como um corpo de conhecimento é criado e estruturado, como uma compreensão particular da sociedade humana e do mundo passou a existir, então, como Foucault, vejo a prisão não como uma instituição isolada, mas como algo representativo das formas em que o conhecimento colonial foi construído e implantado. Ao fazer essa conexão com o poder colonial, eu estou bem ciente de que o sistema de conhecimento e poder que Foucault 
descreveu não foi definido pelas operações do Estado ou pelas aspirações de uma única classe [...] Em geral, então, eu diria que a ampla sinopse de Foucault permanece altamente relevante para qualquer discussão sobre o que poderia ser chamado de "a colonização do corpo" (ARNolD, 1997, p. 148, em livre tradução).

Aqui encontramos uma clara tensão relativa ao comprometimento com metodologias que podem oferecer distintas compreensões políticas do mesmo fenômeno. Arnold (1997) afirma que a ênfase no impacto psicológico do colonialismo focaliza preferencialmente a classe média, ao invés da experiência subalterna, e que isso tende a passar por cima da questão do corpo, sem problematizá-la - sua apropriação física e implicação ideológica nos processos múltiplos do domínio colonial e da hegemonia ocidental. Ao introduzir a frase "colonização do corpo", o autor pretende enfatizar três elementos fundamentais: o processo de incorporação física, o processo de incorporação discursiva e ideológica, e a área de contestação entre entendimentos diferentes do corpo, envolvendo as reivindicações concorrentes para falar do corpo do colonizado e suas necessidades materiais, sociais e culturais.

$\mathrm{Na}$ Índia, o sistema prisional ajudou a desenhar a linha de demarcação entre o domínio colonial, que via a si mesmo como o único racional e humano, e o "barbarismo" de uma fase anterior ou da sociedade "nativa". A prisão emergiu como uma preocupação britânica em extrair impostos e manter a lei e a ordem. No entanto, pressões ocidentais para criar um sistema prisional mais eficiente e "humano" provocaram mudanças. Apesar da retenção de muitos vestígios "barbáricos" de uma era passada, a Inglaterra reivindicou ter introduzido um regime mais humano de punição, que a Índia jamais havia conhecido.

Até o meio do século XIX, as prisões na Índia eram lugares incertos de encarceramento, que requeriam segurança e identidade institucional. Mulheres, nesse contexto, formavam apenas uma pequena parte da população presa, e muito pouco foi feito para sua acomodação e supervisão, o que contribuiu para que elas fossem geralmente relegadas às piores partes da prisão. Outras áreas de demarcação estavam relacionadas à descendência e à raça. Prisioneiros europeus invariavelmente recebiam tratamento especial. O controle da classe trabalhadora branca era relegado às instituições e práticas especiais - orfanatos, asilos, hospitais e repatriação. A administração achou que era também prudente reconhecer a importância das castas entre os aprisionados. Embora não oficialmente, as castas eram vistas como um fator muito potente para ser ignorado no cotidiano das prisões. 
Se a prisão colonial fornecia um modelo orientalista de uma sociedade construída em torno de um essencialismo de casta e religião, ela se tornou, progressivamente, enquanto o século progredia, também um modelo de ordenamento da sociedade segundo os ditames da ciência médica e sanitária. Uma das poucas áreas nas quais o Estado colonial teve relativo acesso desobstruído ao corpo de seus sujeitos, a prisão ocupou um lugar crítico no desenvolvimento do conhecimento e da prática médica ocidental na Índia (ARNOLD, 1997, p. 166, em livre tradução).

Arnold conclui que, paradoxalmente, especialmente nas últimas décadas do século XIX e início do século XX, a prisão foi o lugar onde o colonialismo estava apto a observar e interagir com seus sujeitos em um nível excepcional. O corpo do prisioneiro foi disciplinado menos a serviço de uma reforma moral do que como um componente da remuneração do trabalho. Enquanto a necessidade de respeitar os atributos essenciais de casta e religião foi reconhecida e mantida pelos manuais na prisão, o corpo dos prisioneiros poderia servir também como lugar de intensa pesquisa médica e experimentação. O corpo do prisioneiro e as práticas culturais em torno dele foram constantemente relacionados a percepções mais elevadas e imperativas, de modo semelhante entre colonizados e colonizadores (ARNOLD, 1997, p. 171-172).

O corpo desempenha um papel essencial no argumento dos que buscam se apropriar de uma perspectiva foucaultiana no que concerne ao exercício do poder. Guha também foi um dos que, envolvido com ideias marxistas, desenvolveu alguns dos métodos e temas estimulados pela leitura de Foucault - especialmente a questão do corpo como o lugar onde a dominação colonial reside. Em Chandra's Death (1997b), o antigo editor do coletivo subalternista analisa três deposições sobre a morte, em 1942, de uma mulher chamada Chandra Chashini. Nesta ocasião, segundo Guha, o aparato corriqueiro da historiografia é de pouca ajuda. Como resultado,

[...] o conhecimento histórico desenvolveu, por meio de uma prática recursiva, uma tradição que tende a ignorar o drama pequeno e o detalhe fino da existência social, especialmente em suas profundidades mais baixas. Uma historiografia crítica pode resolver essa lacuna, se voltando para mais perto do chão a fim de colher os traços da vida subalterna em sua passagem pelo tempo (GuHA, 1997b, p. 36, em livre tradução). 
Ainda que com toda sua autenticidade, os testemunhos analisados continuam não satisfazendo, na opinião do autor, uma condição importante requerida pela "prática normal da historiografia" - a condição da contextualidade. Guha acredita que seria de grande ajuda situar o fragmento em séries, de modo a neutralizar os efeitos dessa descontextualização. Os princípios segundo os quais uma série é construída e o caráter da autoridade em construção são todos relevantes para uma compreensão do que é serializado. Essa busca se torna difícil devido à mediação da lei. Aqui, Foucault tem um papel importante, uma vez que, como Guha destaca:

Cada uma das declarações nesse documento é em discurso direto, mas é um discurso incitado pelos requerimentos de uma investigação oficial para o que se presumiu ser um assassinato. "Assassinato é o ponto no qual a história intersecta com o crime" diz Foucault, e o lugar desta intersecção é, de acordo com ele, a "narrativa do crime" (GuHA, 1997b, p. 37-38, em livre tradução).

Assumir a criminalidade e ainda excluir a vontade particular do chamado criminoso e substituir a factualidade vazia de um mero "estado de coisas" para a única experiência positiva da "perda" de Chandra manteria seus autores e suas experiências fora da história. A família de Chandra pertencia aos chamados Bagdis, que estavam entre os mais baixos na escala de classe e casta, de tal modo que uma descrição autoritária na literatura oficial os localizou além do limite da sociedade de dominação de casta hindu, do lado de fora da própria história. Uma exploração abrangente - econômica e cultural - a que foram submetidos lhes roubou o prestígio.

Segundo Guha (1997b), foi a elite de casta superior que dominava essa comunidade que fez as mulheres Bagdi “presas da luxúria masculina”. Elas figuravam ainda como criaturas de "vida fácil” na tradição patriarcal, preparadas para servir como objetos de "satisfação sexual". As pressões exercidas por tamanha moralidade patriarcal poderiam tensionar os recursos de uma comunidade inteira de Bagdis a um ponto de ruptura - o que parece ter acontecido na instância analisada por Guha em seu artigo. Chandra engravidou em um "caso de amor ilícito" e foi medicada com o intuito de abortar, mas acabou morrendo nesse procedimento. A mãe de Chandra, viúva, levou a família ao centro dessa crise - a gravidez de Chandra e os esforços para terminá-la envolveram o resto da família nos desenvolvimentos que se seguiram. Gayaram, seu filho, sendo casado, mobilizou a assistência familiar de sua esposa. Seu cunhado, seu tio e Gayaram sozinhos foram responsáveis 
por remover o corpo e enterrá-lo. Ou seja, o espaço da autoridade masculina da família da viúva teve de ser preenchido por outra família aliada pelo casamento.

A solidariedade inspirada por essa crise teve base territorial, agrupando vilas. Juntas, elas formaram uma região de parentesco Bagdi formada por seis famílias, todas colocadas em risco com a gravidez ilícita de Chandra - que era socialmente proibida. Nesse ponto, Guha (1997b) propõe um paralelo com as análises de Foucault sobre o desenvolvimento da sexualidade na Europa para entender a história indiana:

Na Índia do século XIX, a sexualidade estava subsumida e aliada a todas as transações sociais - ao casamento, parentesco, e "transações de nomes e posses" - assim como às teorias que as informavam. O controle da sexualidade, portanto, era delegado àquelas autoridades e instrumentos - panchayats (conselhos de aldeia), prescrições, proibições e assim por diante - que governavam o sistema de alianças. Falando especificamente da Bengali rural, se poderia dizer que o governo da sexualidade lá residia dentro da jurisdição samak (comunidade, um termo no qual os aspectos institucionais da sociedade e seus atributos morais e políticos são felizmente colapsados) (GuHA, 1997b, p. 45-46, em livre tradução).

As lembranças daquela noite de violência - sobre o corpo de Chandra - se combinaram para produzir um anúncio que desafia as regras da artimanha da lei e que confere dignidade a um trágico discurso. Historicamente, o aborto era o único meio disponível para mulheres derrotarem a moralidade verdadeira, que fazia a mulher, sozinha, culpada por um nascimento ilícito. Foi no domínio do corpo feminino, como Guha (1997b) aponta, ao citar Simone de Beauvoir, que a "gravidez foi acima de tudo, um drama encenado dentro da própria mulher"4.

Na questão da mulher, propriamente, Spivak (1988) considera que os Subaltern Studies foram cuidadosos em suas considerações. Os momentos nos quais homens e mulheres permanecem juntos em um conflito, e nos quais sofrem juntos

4 Um ponto crucial, nesse contexto, consiste nas formas de dominação particulares que o poder colonial destinou às mulheres. Edward Said (1988) nos lembra, nesse ponto, que se a história subalterna é construída para ser um empreendimento separatista - tanto quanto alguns escritos feministas basearam-se na noção de que as mulheres tinham voz e espaço para elas mesmas, inteiramente separadas do domínio masculino -, então se corre o sério risco de que essa história se converta apenas no espelho invertido da escrita tirânica que está em disputa; assim como é possível ser tão exclusivista, limitado, provincial, discriminatório e repressivo quanto os maiores discursos do colonialismo e do elitismo. É importante chamar a atenção para esse risco e para possíveis críticas, contrapondo-o à alternativa subalterna proposta por Guha, que visa um conhecimento integrativo capaz de abranger todas as lacunas, lapsos e ignorâncias dos quais o grupo se diz tão consciente. 
por suas condições materiais de trabalho e de educação, são registrados como uma discriminação tanto de gênero, como de classe, embora a autora considere que não se dê o devido enfoque à importância do conceito-metafórico "mulher" para a funcionalidade deste discurso. Através de uma determinada leitura, a figura da mulher pode ser instrumental ao mudar a função dos sistemas discursivos, como uma mobilização insurgente (SPIVAK, 1988, p. 30-34).

Para Spivak, "relatar, ou melhor ainda, participar do trabalho antissexista entre as mulheres de cor ou as mulheres sob a opressão de classe no Primeiro ou no Terceiro Mundo está inegavelmente na ordem do dia” (SPIVAK, 2010, p. 86). Ignorar o projeto antissexista ou feminista é um gesto político não reconhecido que tem, para a crítica indiana, uma longa história, que contribui para um radicalismo masculino que torna o lugar do investigador transparente, inquestionável. A autora sustenta que não se deve tentar falar ao sujeito historicamente emudecido, mas é necessário ouvi-lo e falar em nome dele. O intelectual pós-colonial não pode deixar de cumprir sua função histórica e crítica. Ao insistir na produção do sujeito imperialista e, ao elaborar considerações sobre as indagações "pode o subalterno falar?” e "pode a mulher subalterna falar?”, Spivak recorre à abolição britânica do ritual hindu das viúvas, em uma sentença inspirada em Freud: "homens brancos estão salvando mulheres de pele escura de homens de pele escura" (SPIVAK, 2010, p. 91). Em oposição a essa visão está o argumento indiano nativo: "as mulheres realmente queriam morrer" (SPIVAK, 2010, p. 94). As duas sentenças vão longe na tentativa de se legitimarem, mas o que a autora questiona é o que isso significa: "a imagem do imperialismo como o estabelecedor da boa sociedade é marcada pela adoção da mulher como objeto de proteção de sua própria espécie” (SPIVAK, 2010, p. 98). Encurralada entre a tradição e a modernização, entre o patriarcado e o imperialismo, a figura da mulher desaparece.

Em resposta a sua principal questão, Spivak responde: "o subalterno não pode falar" (SPIVAK, 2010, p. 126). A autora indiana, entretanto, insiste que o intelectual não pode se esquivar de seu papel. O caminho designado aqui é eminentemente político - para ela a representação não definhou, a mulher intelectual enquanto intelectual tem uma tarefa circunscrita que não deve rejeitar como um floreio.

Partha Chatterjee é outro autor que chama a atenção para a "questão da mulher" dentro do grupo dos Subaltern Studies. Em The Nation and Its Women (1997), Chatterjee destaca que esse é um dos problemas centrais presentes nos mais controversos debates em torno da reforma social do início ao meio do século XIX em Bengali - período considerado como a "renascença". A chamada modernização teve início na primeira metade desse século devido à penetração 
das ideias ocidentais. Para Chatterjee (1997), depois de obterem certo sucesso, os movimentos de reforma delineados como atividades políticas populares enfrentaram um declínio perceptível. Com a política nacionalista que tendia a defender o tradicional e a glorificar o passado indiano, toda tentativa de mudar costumes e estilos de vida começou a ser vista como imitação das maneiras ocidentais e, por isso, consideradas duvidosas. Consequentemente, o nacionalismo adotou uma distinta atitude conservadora para as crenças e práticas sociais, e o movimento em direção à modernização foi instalado pela política nacionalista.

Chatterjee (1997) cita Sumit Sarkar, ao argumentar que as limitações da ideologia nacionalista - ao encampar uma campanha por mudança liberal, social e igualitária - não podem ser vistas como regresso a uma anterior fase radical reformista. Elementos fundamentais de conservadorismo social, tais como a manutenção das distinções de castas e formas patriarcais de autoridade na família, bem como a preferência antes por mudanças simbólicas do que substantivas nas práticas sociais, já eram evidentes nos movimentos de reforma do começo e meio do século XIX. Nesse âmbito, o autor nos questiona sobre qual teria sido a peneira ideológica através da qual se importaram novas ideias provenientes da Europa. Em sua opinião, seria possível situar melhor a questão da mulher na esfera das reivindicações nacionalistas através da reconstrução dessa estrutura ideológica. $\mathrm{O}$ argumento de Chatterjee é o de que a relativa falta de importância da questão da mulher é explicada pelo sucesso nacionalista em situar a "questão da mulher" em um domínio "interior" da soberania, removido da arena de contestação política ao Estado colonial. Esse domínio "interior" da cultura nacional foi constituído, segundo ele, à luz da descoberta da "tradição" (ChatterJEe, 1997, p. 240-241).

$\mathrm{O}$ autor destaca que nas discussões acerca da questão da mulher na pauta de reforma social indiana no começo do século XIX pouco se considerava sobre a específica condição da mulher dentro de um campo particular de relações sociais, privilegiando-se o encontro político entre o Estado colonial e a suposta "tradição de pessoas conquistadas, tradição essa que foi produzida pelo discurso colonial. Uma vez que o novo significado da dicotomia lar e mundo - espiritual e material - é ligado à identificação dos papéis sociais por gênero, é possível ver a estrutura ideológica dentro da resposta dada pelo nacionalismo à questão da mulher (CHATTERJEE, 1997, p. 244-246). As mulheres eram vistas como uma forma específica de espiritualidade, distinta da do homem, mas que não as prevenia, necessariamente, de participar da vida pública e social. Se, por um lado, o movimento nacionalista concebeu a si mesmo como meio de regular a questão das mulheres, por outro, queria dizer que essa não era uma parte fundamental de sua negociação com 
o Estado colonial. Se a vida das mulheres não mudou drasticamente durante o período de agitação nacionalista, Chatterjee afirma que elas não foram, entretanto, excluídas da concepção do novo Estado-Nação.

\section{CONSIDERAÇÕES FINAIS}

Apesar do pensamento de Foucault confrontar diretamente ideias comumente vinculadas ao marxismo, o coletivo indiano não pareceu entendê-lo como um antimarxista. Estabeleceu-se, a partir de então, que há uma forma de exercício do poder que leva em conta as classes - sem, no entanto, tomá-las como centrais à análise. Nesse sentido, tal perspectiva não é abandonada, assim como não o são, Marx e Gramsci. Torna-se mais difícil, entretanto, compreender como o grupo se posicionou politicamente a partir desse eclético ponto de vista.

Mesmo endereçando sua crítica à forma tradicional de pensar sobre o poder e a política, Foucault procurou estabelecer uma nova forma de análise do poder, visto como descentralizado, difuso e metodologicamente organizado em torno de relações de forças antagônicas. Neste artigo, foi possível observar como a metodologia foucaultiana foi usada em algumas das contribuições subalternistas, de forma a problematizar a interpretação da história indiana. As análises apresentadas estavam fortemente marcadas por suas sugestões a respeito de um modelo moderno de crítica das relações de poder.

Tendo como pano de fundo as sugestões foucaultianas, os Subaltern Studies passaram a destacar a fragmentação e a pluralidade, afirmando a diferença. Com isso, possibilitaram que as narrativas suprimidas dos despossuídos fossem ouvidas e que se subvertesse o discurso dominante que impunha, como meio de facilitar a colonização dos não-europeus, a racionalidade eurocêntrica (CHANDAVARKAR, 2000). Sumit Sarkar (2000) afirma que essa "virada” levou os Subaltern Studies a uma crescente ênfase no discurso colonial e, com isso, a uma preocupação também crescente com as fundações intelectuais do colonialismo. Os subalternistas passaram a desconstruir o discurso colonial com o objetivo de expor o eurocentrismo do conhecimento pós-colonial.

Como aponta Rajnarayan Chandavarkar (2000), a consequência não prevista dessa nova fase subalternista foi a de reestabelecer, ainda que não intencionalmente, o eurocentrismo na história do sul da Ásia:

O discurso colonial, segundo foi argumentado, construiu uma sociedade indiana e representou os seus sujeitos em formas que facilitaram sua subordinação 
e pela qual eles absorveram, apropriaram e aplicaram a si mesmos. Foi porque as formas de autoridade e domínio no trabalho eram embebidas na "classe trabalhadora", que Chakrabarty argumentou que trabalhadores adquiriram "uma presença ativa em todo o processo de disciplinamento". Eles eram, em outras palavras, cúmplices de sua própria subordinação e agentes ativos do processo de se tornarem impotentes. Não só essa afirmação privava o subalterno de qualquer poder de agência, mas sugeria também que os governantes coloniais eram a única força em movimento na história indiana. Assim, a odisseia pós-moderna encalhou seus tripulantes em costas familiares (ChandaVARKAR, 2000, p. 65, em livre tradução).

Como indica Chandavarkar (2000), e também O’Hanlon e Washbrook (2000, p. 191), as perspectivas pós-estruturalistas se fundiram à “odisseia pós-moderna”, num amálgama característico de crítica cultural, análises foucaultianas de poder, engajamento com a "política da diferença" e ênfases no descentralizado e heterogêneo. Em consonância com essas críticas, Fredric Jameson (2002) destaca como essas novas tendências culturais - que debocham do autoconfiante evolucionismo secular da modernidade - restringiram severamente o espaço para o florescimento de um pensamento crítico radical. Isso porque, como aponta Jameson, é difícil imaginar como se pode construir um programa político atraente acreditando-se no "fim da história" e excluindo do pensamento político a dimensão do futuro e da mudança radical. Assim, o conceito de modernidade que supunham ingenuamente ter sido desbancado há muito, se reinventa:

O propalado triunfo ocidental tem sido persistentemente comemorado, em termos explicitamente pós-modernos, como a vitória dos velhos valores modernistas, utópicos e produtivistas, tais como o "fim" da ideologia e também da história, e a doxa nominalista do específico e da Diferença, quer estejam essas coisas articuladas em linguagens de esquerda ou de direita (na verdade, a renúncia a qualquer distinção entre esquerda e direita é muitas vezes a peça central dessa retórica "pós-moderna") (JAMESON, 2002, p. 15).

O interessante do argumento de Jameson (2002), nesse ponto, é a sua interpretação de que a introdução do termo "moderno" é parte primordial de uma batalha política e discursiva. Para o crítico marxista, há uma incoerência conceitual e filosófica nesse renascimento do conceito de modernidade. O que se quer dizer, de modo geral, na polêmica contra o socialismo e o marxismo, é que essas posições 
estão "fora de moda”, por estarem ainda comprometidas com o paradigma básico do modernismo. Para escapar dessas "tiranias", no caso da historiografia indiana, dever-se-ia voltar para as "mitografias”, para as histórias escondidas das vítimas do colonialismo, "que vão expor o caráter mítico das fábulas coloniais e pós-coloniais da modernidade" (O'HANLON; WASHBROOK, 2000, p. 194). Mas modernismo entendido aqui como algum campo já ultrapassado de planejamento de cima para baixo, seja ele do governo, da economia ou da estética, um lugar de poder centralizado, em profunda discordância com os valores da descentralização e dos aspectos característicos de qualquer "novo sistema pós-moderno". O que significa classificar esse novo sistema, então, como "pós"-moderno? Jameson realiza sua teorização acerca do "pós-modernismo" como a experiência vivida do chamado "capitalismo tardio".

Como afirmam O’Hanlon e Washbrook (2000), o capitalismo de fato constitui um sistema ou processo, inerentemente conflitivo e inconstante, que produz e opera a partir de uma grande variedade de relações sociais de produção e exploração, em constante transformação. Embora suas forças possam formar modos de resistências, elas não predeterminam os resultados, pois nenhum sistema hegemônico pode permear e esgotar toda experiência social, muito menos um que falha em atender tantas necessidades sociais e humanas.

Como muitos críticos apontam, é difícil ver como qualquer engajamento político é possível na visão foucaultiana de poder deliberadamente amorfo e disperso. Tal engajamento é ainda menos promissor quando se afirma que a sua maior virtude é a recusa intelectual em aceitar o próprio tema da modernidade capitalista:

É ainda menos claro como se pode gerar o que em última análise é uma política de emancipação a partir de suposições foucaultianas sobre o poder e as relações sociais [...] muitos dos que partilham suas abordagens vigorosamente e virtuosamente afirmam a presença de conflito em todas as relações sociais, dizendo muito pouco a respeito dos meios políticos pelos quais a emancipação deve ser perseguida ou com o que, de fato, possa parecer se fosse já alcançada. De acordo com essa visão, a emancipação se torna um conflito puramente interno à consciência daqueles que resistem e apenas representáveis por eles (O'HANLON; WASHBROOK, 2000, p. 201, em livre tradução).

Daí a dificuldade dos Subaltern Studies, em sua fase pós-estruturalista, em lidar com questões de subjetividade e, portanto, de história e agência, e sobre a necessidade de repensar a relevância da dialética marxiana da modernidade, afir- 
mando não ter lógica a divisão da saga da humanidade em "história e pós-história". Afirma Göran Therborn:

Já que não parece provável que o capitalismo ou suas polarizações de percurso de vida venham a desaparecer no futuro próximo, há uma boa chance de que o fantasma de Marx continue a perseguir o pensamento social. O modo mais óbvio de seguir a teorização social inspirada em Marx será olhar para o que acontece hoje com o venerável dístico das forças e relações de produção em escala global e seus efeitos conflituosos sobre as relações sociais. O marxismo pode não ter mais soluções prontas, mas sua agudeza crítica não perdeu necessariamente o fio (THERBORN, 2012, p. 94).

\section{REFERÊNCIAS BIBLIOGRÁFICAS}

ARNOLD, D. "Touching the Body: Perspectives on the Indian Plague”. In: GUHA, R; SPIVAK, G. (Org.). Selected Subaltern Studies. New York: Oxford University Press, 1988, p. 391-426.

"The Colonial Prison: Power, Knowledge, and Penology in NineteenthCentury India”. In: GUHA, R. (Org.). Subaltern Studies Reader, 1986-1995. Minneapolis: University of Minnesota Press, 1997, p. 140-178.

CHAKRABARTY D. Subaltern Studies and Postcolonial Historiography. Views from South, v. 1, n. 1, p. 9-32, 2000 .

Provincializing Europe: postcolonial thought and historical difference. Nova Jersey: Princeton University Press, 200ob.

CHANDAVARKAR, R. "The making of the working class: E.P. Thompson and Indian History”. In: Chatuverdi, V. (org.). Mapping Subaltern Studies and the Postcolonial. London: Verso, 2000, p. 50-71.

CHATUVERDI, V. A Critical Theory of Subalternity: Rethinking Class in Indian Historiography. Left History, v. 12, n. 1, p. 9-28, 2007.

CHATTERJEE, P. "More on Modes of Power and the Peasantry”. In: GUHA, R.; SPIVAK, G. (Org.). Selected Subaltern Studies. New York: Oxford University Press, 1988, p. 351-390.

."The Nation and Its Women". In: GUHA, R. (Org.). A subaltern studies reader 1986-1995. Minneapolis: University of Minnesota Press, 1997, p. 240-262.

FOUCAULT, M. A arqueologia do saber. Rio de Janeiro: Forense Universitária, 2005.

. Em Defesa da Sociedade. Curso no Collège de France (1975-1976). São Paulo: Martins Fontes, 2010. 
GUHA, R. A rule of property for Bengal: an essay on the idea of permanent settlement. Paris: Mouton \& Co., 1963.

. Elementary Aspects of Peasant Insurgency in Colonial India. Durham and London: Duke University Press, 1983.

Dominance without hegemony: history and power in colonial India. Cambridge: Harvard University Press, 1997a.

“Chandra’s Death”. In: GUHA, R. (Org.). A Subaltern Studies Reader 19861995. Minneapolis: University of Minnesota Press, 1997b, p. 34-62.

HARDIMAN, D. Subaltern at Crossroads. Economic and Political Weekly, v. 21, n. 7, p. 288-290, 1986.

JAMESON, F. Modernidade singular: ensaio sobre a ontologia do presente. Rio de Janeiro: Civilização Brasileira, 2002.

MACHADO, R. "Introdução”. In: FOUCAULT, M. Microfísica do poder. Rio de Janeiro: Edições Graal, 2010, p. VII-XXII.

MALLON, F. E. "Promesa y dilema de los Estudios subalternos: perspectivas a partir de la historia latino americana”. In: SANDOVAL, P. (Org.). Repensando la Subalternidad. Miradas críticas desde/ sobre América Latina. Lima: IEP; SEPHIS, 2009, p. 87-116. O'HANLON, R.; WASHBROOK, D. "After Orientalism: Culture, Criticism and Politics in the Third World". In: CHATUVERDI, V. (Org.). Mapping Subaltern Studies and the Postcolonial. London: Verso, 2000, p. 191-219.

PRAKASH, G. "Writing Post-Orientalist Histories of the Third World: Perspectives from Indian Historiography”. In: CHATUVERDI, V. (Org.). Mapping Subaltern Studies and the Postcolonial. London: Verso, 2000, p. 163-190.

RODRÍGUEZ, I. "Reading Subalterns Across Texts, Disciplines, and Theories: From Representation to Recognition”. In: RODRÍGUEZ, I (Org.). The Latin American Subaltern Studies Reader. Durham e London: Duke University Press, 2001, p. 2-32. SARKAR, S. “The Decline of the Subaltern in Subaltern Studies”. In: CHATUVERDI, V. (Org.). Mapping Subaltern Studies and the Postcolonial. London: Verso, 2000, p. 300-323.

SAID, E. "Foreword”. In: GUHA, R.; SPIVAK, G. (Org.). Selected Subaltern Studies. Nova York: Oxford University Press, 1988, p. V-X.

SPIVAK, G. “Subaltern Studies: Deconstructing Historiography”. In: GUHA, R.; SPIVAK, G.

(Org.). Selected Subaltern Studies. New York: Oxford University Press, 1988, p. 3-34. Pode o subalterno falar? Belo Horizonte: Editora UFMG, 2010.

THERBORN, G. Do marxismo ao pós-marxismo? São Paulo: Boitempo, 2012. WILLIAMS, J. Pós-estruturalismo. Petrópolis: Vozes, 2012.

Recebido para publicação em: 30/07/15. Aceito para publicação em: 05/01/2016. 